\title{
Lipid Peroxidation and Some Antioxidant Enzymes Evaluation in Apple Cider Vinegar (ACV) Treated Male and Female Wistar Rats Exposed to Chronic Restraint Stress
}

\author{
R. A. Abdulrauf, F. A. Dawud, N. S. Emmanuel, H. D. Muhammad, A. S. Dange, \\ B. A. David, A. E. Ogweje, A. U. Alexander, M. Yahuza \\ Department of Human Physiology, Faculty of Basic Medical Sciences, College of Health Sciences, \\ Ahmadu Bello University Zaria, Kaduna State, Nigeria \\ Email: oluwakemi2016@gmail.com
}

How to cite this paper: Abdulrauf, R.A., Dawud, F.A., Emmanuel, N.S., Muhammad, H.D., Dange, A.S., David, B.A., Ogweje, A.E., Alexander, A.U. and Yahuza, M. (2018) Lipid Peroxidation and Some Antioxidant Enzymes Evaluation in Apple Cider Vinegar (ACV) Treated Male and Female Wistar Rats Exposed to Chronic Restraint Stress. Advances in Enzyme Research, 6, 21-28.

https://doi.org/10.4236/aer.2018.63003

Received: July 9, 2018

Accepted: September 11, 2018

Published: September 14, 2018

Copyright ( 2018 by authors and Scientific Research Publishing Inc. This work is licensed under the Creative Commons Attribution International License (CC BY 4.0). http://creativecommons.org/licenses/by/4.0/

\begin{abstract}
This study was designed to assess the effect to apple cider vinegar (ACV) on oxidative stress biomarkers in male and female Wistar rats exposed to chronic restraint stress. Severe and persistent stress elevates reactive oxygen species (ROS) production by metabolic and physiological processes; causing cellular damage. Thirty (30) Adult Wistar rats of both sexes weighing about 150 - 200 $\mathrm{g}$ were divided into 3 groups each consisting of a male and female subgroup and given the following treatments once a day for 21 days: Normal control group received $0.5 \mathrm{ml}$ distilled water orally, the restraint stress (RS) group was exposed to chronic restraint stress 6 hours daily while the Apple cider vinegar (ACV)-treated group received $4 \mathrm{ml} / \mathrm{kg}$ of apple cider vinegar orally in addition to chronic restraint stress 6 hours daily. The rats were sacrificed after the experimental period and blood was collected via cardiac puncture for assessing oxidative stress biomarkers. ACV $(4 \mathrm{ml} / \mathrm{kg})$ treatment decreased lipid peroxidation (MDA) and serum catalase (CAT) activity while upregulating endogenous superoxide dismutase (SOD) activity. The findings of this study show that the female Wistar rats are more predisposed to the antioxidant effect of ACV than the males.
\end{abstract}

\section{Keywords}

Apple Cider Vinegar, Superoxide Dismutase, Malondialdehyde, Catalase

\section{Introduction}

Oxidative stress, defined as a measure of steady levels of reactive oxygen species 
(ROS) or oxygen radical in the biological system, is a resultant of over production of free radicals i.e. reactive oxygen species (ROS), which exceeds the body's antioxidant defense mechanisms [1]. Severe and persistent stress elevates reactive oxygen species (ROS) production by metabolic and physiological processes; causing cellular damage [2]. Physical restraint is a well-known stress model, which increases oxidative processes leading to the generation of reactive oxygen species which may propagate the initial attack on lipid rich membranes to cause lipid peroxidation [3]. Excessive reactive oxygen species production resulting from stress hormones leads to an increase in lipid peroxidation of the cellular structures which play an important role in pathogenesis of degenerative diseases, such as atherosclerosis, oxidative damage to DNA, and carcinogenesis. Reactive oxygen species are kept at physiologically optimal levels by the endogenous antioxidant defense systems as well as natural exogenous antioxidants derived from the diet [4]. The endogenous antioxidant system includes the array of antioxidant enzymes; cellular and mitochondrial superoxide dismutases (copper/zinc (CuZnSOD) and Mn2+-dependent superoxide dismutase (MnSOD), catalase (CAT), glutathione peroxidase (GPx) and glutathione reductase (GLR), and non-enzymatic antioxidants such as glutathione (GSH).

Apple cider vinegar (ACV) is a liquid product of fermentation of apples. It has a brownish yellow color and has been in use for hundreds of years. In the year $400 \mathrm{BC}$, Hippocrates, the father of modern medicine prescribed the mixture; oxymel made of honey and apple cider vinegar for treatments of persistent coughs and other diseases [5]. It has been widely used in various dosage forms in alternative medicine for several conditions such as diabetes [6], obesity [7] hypertension [8] and hyperlipidemia [9]. The beneficial effects of apple cider vinegar are attributed to its acetic acid content, apple pectin and other phytochemicals such as polyphenolic compounds and flavonoids [10] [11]. Estrogenic compounds such as female sex hormones are believed to offer antioxidant protection and females are thought to be more resistant to tissue damage from oxidative stress [12]. The aim of this study was to assess the effect of apple cider vinegar $(\mathrm{ACV})$ treatment on some oxidative stress biomarkers in chronic restraint-stressed male and female Wistar rats.

\section{Materials and Methods}

\subsection{Chemicals}

Raw, Organic and Unfiltered Braggs apple cider vinegar (5\% acetic acid) was purchased from Konga Online stores (voucher number \#G049343406), Tricholoroacetic acid (TCA), Thiobabituric acid (TBA), hydrochloric acid ( $\mathrm{HCl})$, phosphate buffer solution, carbonate buffer solution, Adrenaline, Potassium heptaoxochromate (VI), Hydrogen peroxide $\left(\mathrm{H}_{2} \mathrm{O}_{2}\right)$.

\subsection{Experimental Animals}

Thirty adult Wistar rats weighing between $150 \mathrm{~g}$ and $200 \mathrm{~g}$ were used for this 
study. They were purchased, housed and fed under laboratory conditions and had free access to feed and water, and they were acclimatized to laboratory conditions for 2 weeks before commencement of the experiment.

\subsection{Experimental Design}

The thirty (30) Wistar rats were weighed and randomly divided into three groups of ten rats each namely: the normal control group, the restraint stress group and the Apple cider vinegar treated group as shown below:

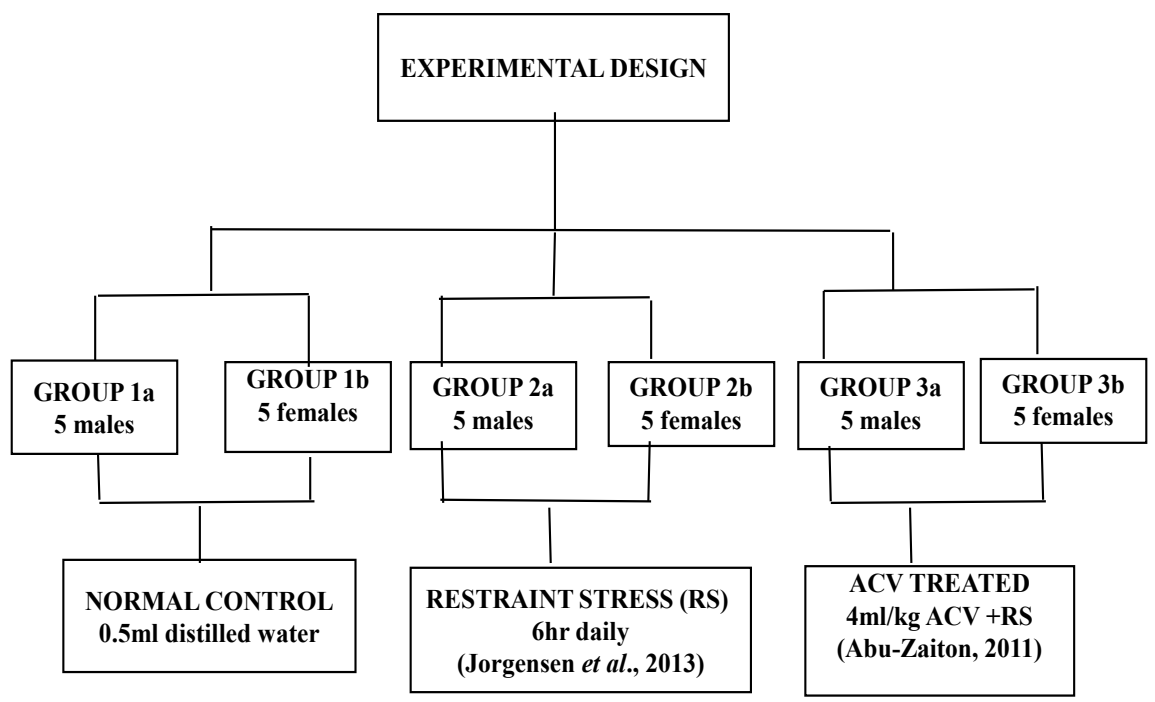

\subsection{Induction of Restraint Stress}

Restraint stress was induced using the method of [13]. Small restraint cages made from perspex were used. Each rat was housed individually in a multi-compartment cage in which they fit in tightly 6 hours daily for 21 days for the induction of restraint stress but the control group was left undisturbed in their cages but without assess to food or water during the restraint period.

\subsection{Collection of Blood Samples}

The animals were sacrificed on the $22^{\text {nd }}$ day under chloroform anaesthesia. $5 \mathrm{ml}$ of blood was drawn from each sacrificed animal from all groups via cardiac puncture. The samples were centrifuged at $3000 \mathrm{~g}$ rpm for 30 minutes and the sera obtained for assessment of oxidative stress biomarkers.

\subsection{Analysis of Biomarker of Lipid Peroxidation}

Lipid peroxidation was measured by the modified method of [14] as described by [15].

\subsection{Determination of Superoxide Dismutase Activity}

Superoxide dismutase (SOD) activity was determined by a method described by [16]. 


\subsection{Determination of Catalase Activity}

Catalase activity was determined using the method described by [17].

\section{Results}

In Table 1, the serum level of MDA (nMol/mg of protein) in the normal control, restraint stress and the ACV treated group; $547.28 \pm 3.33,710.32 \pm 26.45$ and $655.52 \pm 15.49$ respectively was not statistically significant $(p>0.05)$. Serum SOD was statistically significant $(\mathrm{p}<0.05)$ increase in the ACV treated group compared to normal control and restraint stress group. Table 1 also shows the result of serum CAT. There was a statistically significant increase in the group treated with ACV compared to normal and chronic stress groups $(\mathrm{p}<0.05)$.

Table 2 shows the results of serum MDA, SOD and CAT. There was no statistically significant difference in the results of MDA in the treated group. There was however, statistically significant increase in the ACV treated group compared to the normal and chronic stressed group. Serum CAT level was significantly $(\mathrm{p}<0.05)$ increased in restraint stress group compared to normal control. The ACV treated group was statistically decreased compared to restraint stress group.

\section{Discussion}

Oxidative stress reflects an imbalance between the systemic manifestation of reactive oxygen species (ROS) and biological system's ability to readily detoxify the reactive intermediates or to repair the resulting damage. Oxidative stress has been implicated in the development of myriad of diseases [3]. During stress, increased production of reactive oxygen species (ROS) leads to increased lipid peroxidation [1] [18]. The increased serum levels of oxidative stress biomarkers; malondialdehyde, superoxide dismutase and catalase activity seen in the restraint stress rats is indicative of enhanced oxidative stress from the chronic stress induction. Activation of the hypothalamo-pituitary adrenal axis is associated with acceleration in oxidative stress via unbalanced redox, including excessive production of mitochondrial reactive oxygen species [19] [20] [21]. This is in agreement with the work of [3] and [21] who observed a significant increase

Table 1. Effect of Apple Cider Vinegar (ACV) on serum level of Malondialdehyde (MDA), Superoxide dismutase (SOD) and Catalase (CAT) in restraint-stressed Male Wistar rats.

\begin{tabular}{cccc}
\hline Animal Grouping & $\begin{array}{c}\text { Serum MDA } \\
\text { nMol/mg of protein }\end{array}$ & $\begin{array}{c}\text { Serum SOD } \\
\mathrm{U} / \mathrm{ml}\end{array}$ & $\begin{array}{c}\text { Serum CAT } \\
\text { U/mg of protein }\end{array}$ \\
\hline $\begin{array}{c}\text { Normal control } \\
(1 \mathrm{ml} / \mathrm{kg} \text { of distilled water })\end{array}$ & $547.28 \pm 3.33$ & $16.98 \pm 0.5$ & $3.79 \pm 0.32$ \\
$\begin{array}{c}\text { Restraint Stress } \\
(6 \text { hours daily })\end{array}$ & $710.32 \pm 26.45$ & $18.86 \pm 0.21$ & $4.22 \pm 0.19$ \\
$\begin{array}{c}\text { Restraint Stress }+ \text { ACV } \\
\text { treated }(4 \mathrm{ml} / \mathrm{kg})\end{array}$ & $655.52 \pm 15.49$ & $26.52 \pm 0.39^{\mathrm{a}, \mathrm{b}}$ & $5.34 \pm 0.29^{\mathrm{a}, \mathrm{b}}$ \\
\hline
\end{tabular}


Table 2. Effect of Apple Cider Vinegar (ACV) on serum level of Malondialdehyde (MDA), Superoxide dismutase (SOD) and Catalase (CAT) in restraint-stressed Female Wistar rats.

\begin{tabular}{cccc}
\hline Animal Grouping & $\begin{array}{c}\text { Serum MDA } \\
\text { nMol/mg of protein }\end{array}$ & $\begin{array}{c}\text { Serum SOD } \\
\mathrm{U} / \mathrm{ml}\end{array}$ & $\begin{array}{c}\text { Serum CAT } \\
\text { U/mg of protein }\end{array}$ \\
\hline $\begin{array}{c}\text { Normal control } \\
(1 \mathrm{ml} / \mathrm{kg} \text { of distilled water })\end{array}$ & $574.52 \pm 4.05$ & $14.74 \pm 0.22$ & $3.88 \pm 0.29$ \\
$\begin{array}{c}\text { Restraint Stress } \\
(6 \text { hours daily })\end{array}$ & $740.68 \pm 14.8$ & $17.62 \pm 0.66$ & $6.3 \pm 0.14^{\mathrm{a}}$ \\
$\begin{array}{c}\text { Restraint Stress }+\mathrm{ACV} \\
\text { treated }(4 \mathrm{ml} / \mathrm{kg})\end{array}$ & $429.92 \pm 8.15$ & $24.80 \pm 1.11^{\mathrm{a}, \mathrm{b}}$ & $3.67 \pm 0.17^{\mathrm{b}}$ \\
\hline
\end{tabular}

in malondialdehyde levels in restraint stressed rats when compared to the normal control rats. [22] reported sustained elevation in oxidative stress biomarkers; superoxide dismutase, glutathione peroxidase and catalase levels in repeated restraint rats. The elevated levels of biomarkers of oxidative stress in the restraint stress rats disagrees with the findings of [23] who observed an increased malondialdehyde level but attenuated levels of other antioxidant enzymes; superoxide dismutase (SOD), glutathione peroxidase (GPx) and catalase (CAT) activities in stressed rats.

The study did not show any significant consistency regarding sex differences in the level of oxidative stress biomarkers. Although estrogenic compounds are thought to offer antioxidant protection, restraint stressed female rats exhibited a higher level of these stress parameters than their male counterpart except for superoxide dismutase which was slightly higher in the restraint stressed males rats compared to the female rats. This could mean that generation of reactive oxygen species by stress hormones secreted in response to the restraint procedure overrides the antioxidant protection given by the estrogenic compounds. Females have higher stress reactivity than males. This observation agrees with the works of [24] [25] who also observed relatively higher level of oxidative stress in female rats than male rats. Estrogen exerts an antioxidant effect and its level positively correlates with plasma antioxidant capacity and antioxidant enzymes expression throughout the menstrual cycle and negatively with lipid peroxides, the product of oxidative damage. Estrogen replacement therapy (ERT) restores total plasma antioxidant capacity and decreases lipid peroxides the antioxidant effect of estrogen may be related to a direct free radical scavenging activity or upregulation of antioxidant enzymes [12].

Apple cider vinegar treatment attenuated serum Malondialdehyde activity; this could be due to a possible adaptogenic effect of apple cider vinegar in ameliorating the excessive lipid peroxidation that may have occurred in the animals due to chronic stress. The polyphenols in Apple Cider Vinegar (ACV) may have acted by interrupting the free-radical chain of oxidation by donating hydrogen from phenol's hydroxyl groups, thereby forming stable free radicals, which do not initiate or propagate further oxidation of lipids [4]. Flavonoids especially catechins which are present in apple cider vinegar have been shown to reduce low 
density lipoprotein (LDL) oxidation [26]. This is in agreement with work of [4] who observed a decrease in lipid peroxidation in the lens of ovariectomized mice treated with apple cider vinegar. Decreased lipid peroxidation as evidenced by lower level of serum malondialdehyde activity in female rats may be due to the effect of female sex hormones which have been established to have antioxidant ability in addition to the antioxidant effect of the ACV thereby causing a significant decrease in lipid peroxidation in females than in males. The observation that females were significantly less sensitive to this oxidative stress was the first indication of a possible protection afforded to women that may be due at least in part to circulating hormones such as oestrogen. Research in subsequent years has demonstrated the antioxidant effect of estrogen as the main mechanism by which female sex hormones protect tissues from oxidative damage [24]. Apple cider vinegar decreased lens oxidative injury by modulating GSH-Px in mice fed with high cholesterol [4]. This is by virtue of its rich phenolic content as well as its flavonoids and carotenoids. Phenolic compounds are secondary metabolites in plants and plant products that contribute to their antioxidant activities Antioxidant strength is measured by both phenolic and non-phenolic compounds, as they reverse free radical activities by decomposing peroxides and unpaired oxygen molecules, and adsorbing and neutralizing the free radicals to render them harmless to the body [11]. The increased serum level of superoxide dismutase activity observed in the male and female ACV treated rats could be due to the antioxidant effect of ACV which may have enhanced the antioxidant capability of the rats or may have upregulated the release of endogenous superoxide dismutase in response to increased oxidative stress. ACV has been reported to be rich in minerals such as copper, zinc, potassium etc. this may have assisted in enhancing the synthesis of superoxide dismutase in response to the increased oxidative stress. Additionally, Phenolic acids as well as vitamins in ACV can scavenge superoxide anion and free radicals in vivo resulting in a potent antioxidant activity [26]. The mild decrease in serum catalase activity in the ACV treated group could be in part, by the antioxidant activity of ACV in inhibiting over production of reactive oxygen species by virtue of its high concentrations of flavonoids, anthraquinones and triterpenes as revealed by preliminary phytochemical screening carried out as well as quercetin, catechin, phloridzin and chlorogenic acid, all of which are strong antioxidants and can contribute to adaptogenic activity [4].

\section{Conclusion}

Apple cider vinegar (ACV) was found to significantly decrease lipid peroxidation and oxidative stress in male and female rats, exposed to chronic restraint stress 6 hours daily for 21 days. From this study, it appears that females are more responsive to antioxidant treatment.

\section{Conflicts of Interest}

The authors declare no conflicts of interest regarding the publication of this paper. 


\section{References}

[1] Mallick, A.K., Das, B., Ahsan, M., Saxena, S., Samanta, S. and Kumari, N.A. (2015) Correlation Study between Lipid Peroxidation and Dyslipidemia in Postmenopausal Women. Scholars Journal of Applied Medical Sciences, 3, 669-673.

[2] Budak, N.H., Aykin, E., Seydim, A.C., Greene, A.K. and Guzel-Seydim, Z.B. (2014) Functional Properties of Vinegar. Journal of Food Science, 79, 757-764. https://doi.org/10.1111/1750-3841.12434

[3] Fyiad, A.A. (2012) Anti-Stress Effects of Camellia sinensis in Rats Subjected to Restraint Stress. Report and Opinion, 4, 23-30.

[4] Nazıroglu, M., Güler, M., Küçükayaz, M., Övey, I.S. and Özgül, C. (2012) Apple Cider Vinegar Supplementation Modulates Lipid Peroxidation and Glutathione Peroxidase Values in Lens of Ovariectomized Mice. Cell Membranes and Free Radical Research, 3, 209-214.

[5] Johnston, C.S.S. and Gaas, C.A. (2006) Vinegar; Medicinal Uses and Antiglycemic Effect. Medscape General Medicine, 8, 61.

[6] Mahmoodi, M., Hosseini-Zijoud, S., Hassanshahi, G., Nabati, S., Modarresi, M., Mehrabian, M., Sayyadi, A. and Hajizadeh, M. (2013) The Effect of White Vinegar on Some Blood Biochemical Factors in Type 2 Diabetic Patients. Journal of Diabetes and Endocrinology, 4, 1-5.

[7] Iman, M., Moallem, S.A. and Barahoyee, A. (2015) The Effect of Apple Cider Vinegar on Blood Glucose in Diabetic Mice. Pharmaceutical Sciences, 20, 163-168.

[8] Jabir, H.B., Abbas, F.N. and Khalaf, R.M. (2011) In Vitro Assessment of Antifungal Potential of Apple Cider Vinegar and Acetic Acid versus Fluconazole in Clinical Isolates of Otomycosis. Thi-Qar Medical Journal, 1, 126-133.

[9] Hamed, A.T. and Matar, R.A. (2014) The Effect of Apple Cider Vinegar and Grape Vinegar on Lipid Profile in Albino White Rats. Jordan Journal of Pharmaceutical Sciences, 7, 164-170. https://doi.org/10.12816/0027040

[10] Soltan, S.A.S. and Shehata, M.E.M. (2012) Antidiabetic and Hypocholesterolemic Effect of Different Types of Vinegar in Rats. Life Science Journal, 9, 2141-2151.

[11] Mohamad, N.E., Yeap, S.K., Lim, K.L., Yusof, H.M., Beh, B.K., Tan, S.W., Ho, W.Y., Sharifuddin, S.A., Jamaluddin, A., Long, K., Abd Rahman, N.M.A. and Alitheen, N.B. (2015) Antioxidant Effects of Pineapple Vinegar in Reversing of Paracetamol-Induced Liver Damage in Mice. Chinese Medicine, 10, 3.

https://doi.org/10.1186/s13020-015-0030-4

[12] Bellanti, F., Matteo, M., Rollo, T., DeRosario, F., Greco, P., Vendemiale, G. and Serviddio, G. (2013) Sex Hormones Modulate Circulating Antioxidant Enzymes: Impact of Estrogen Therapy. Redox Biology, 1, 340-346. https://doi.org/10.1016/j.redox.2013.05.003

[13] Smith, C. (2012) Using Rodent Models to Simulate Stress of Physiologically Relevant Severity: When, Why and How. In: Qian, X.X., Ed., Chapter 10 Glucocorticoids. New Recognition of Our Familiar Friend, Intech, 211-230.

[14] Niehaus, W.G. and Samuelsson, B. (1968) Formation of Malondialdehyde from Phospholipid Arachidonate during Microsomal Lipid Peroxidation. European Journal of Biochemistry, 6, 126-130. https://doi.org/10.1111/j.1432-1033.1968.tb00428.x

[15] Akanji, M.A., Adeyemi, O.S., Oguntoye, S.O. and Suleiman, F. (2009) Psidium Guajava Extract Reduces Trypanosomiasis Associated Lipid Peroxidation and Raised Glutathione Concentrations in Injected Animals. Excli Journal, 8, 148-154.

[16] Fridovich, I. (1986) Superoxide Dismutases. In: Meister, A., Ed., Advances in En- 
zymology, Vol. 58, John Wiley and Sons, New York, 61-97. https://doi.org/10.1002/9780470123041.ch2

[17] Sinha, K.A. (1972) Colorimetry Assay of Catalase. Analytical Biochemistry, 47, 389-394. https://doi.org/10.1016/0003-2697(72)90132-7

[18] Abu-zaiton, A.S. (2011) Effect of Apple Vinegar on Physiological State of Pancreas in Normal and Alloxan Induced Diabetic Rats. World Journal of Zoology, 6, 7-11.

[19] Kim, H.G., Kim, Y.J., Ahn, Y.C. and Son, C.G. (2015) Serum Levels of Stress Hormones and Oxidative Stress Biomarkers Differ According to Sasang Constitutional Type. Evidence-Based Complementary and Alternative Medicine, 2015, Article ID: 737631.

[20] Jorgensen, A., Maigaard, K., Wörtwein, G., Hageman, I., Henriksen, T., Weimann, A., Peter Møller, P., Loft, S., Hau, J., Poulsen, H.E. and Jorgensen, M.B. (2013) Chronic Restraint Stress in Rats Causes Sustained Increase in Urinary Corticosterone Excretion without Affecting Cerebral or Systemic Oxidatively Generated DNA/RNA Damage. Progress in Neuro-Psychopharmacology and Biological Psychiatry, 40, 30-37.

[21] Ozkol, H., Koyuncu, I. and Tuluce, Y. (2011) Some Medicinal Plants Counteract Alterations of Neuroendocrine Stress Response System, Oxidative and Nitrosative Stress Caused by Repeated Restraint in Rats. Journal of Medicinal Plants Research, 5, 4360-4368.

[22] Abd-Aziz, N.A.A., Chatterjee, A., Chatterjee, R. and Durairajanayagam, D. (2014) Corticosterone-Induced Oxidative Stress Alters Epididymal Sperm Fertility in Rats. ASM Science Journal, 8, 117-124.

[23] Bowman, R.E., Zrull, M.C. and Luine, V.L. (2001) Chronic Restraint Stress Enhances Radial Arm Maze Performance in Female Rats. Brain Research, 904, 279-289.

[24] Malisch, J.L., Saltzman, W., Gomes, F.R., Rezende, E.L., Jeske, D.R. and Garland, T. (2007) Baseline and Stress-Induced Plasma Corticosterone Concentrations of Mice Selectively Bred for High Voluntary Wheel Running. Physiological and Biochemical Zoology, 80, 146-156. https://doi.org/10.1086/508828

[25] Sertoki, M., Asgary, S., Eidi, A., Rohani, A.H. and Esmaeu, N. (2009) Effects of Apple Juice on Risk Factors of Lipid Profile, Inflammation and Coagulation, Endothelial Markers and Atherosclerotic Lesions in High Cholesterolemic Rabbits. Lipids in Health and Disease, 8, 39.

[26] Wactawski-Wende, J., Schistermand, E.F., Hoveya, K.M., Howards, P.P., Browne, R.W., Hedigerd, M., Liud, A. and Trevisan, M. (2009) BioCycle Study: Design of the Longitudinal Study of the Oxidative Stress and Hormone Variation during the Menstrual Cycle. Paediatric Perinatal Epidemiolology, 23, 171-184.

https://doi.org/10.1111/j.1365-3016.2008.00985.x 